\title{
Quando a língua portuguesa visita a Libras: explorando o design thinking e o contato entre línguas no Ensino Médio
}

\author{
Isaias dos Santos Ildebrand ${ }^{1}$ \\ Cátia de Azevedo Fronza ${ }^{2}$ \\ Simone Weide Luiz $^{3}$ \\ Programa de Pós-Graduação em Linguística Aplicada, UNISINOS, São Leopoldo, RS, Brasil
}

Resumo: Este artigo é um recorte de uma pesquisa de Mestrado desenvolvida por Ildebrand (2020). Busca-se descrever e apresentar uma ação de ensino concebida nas aulas de língua materna de alunos ouvintes do Ensino Médio de uma escola localizada na região metropolitana de Porto Alegre. Assim, nas aulas de Língua Portuguesa (língua majoritária) oportunizou-se espaço e valorizou-se a Língua Brasileira de Sinais, Libras (língua minoritária). Alunos e professor foram mobilizados a delinear soluções para problemas relacionados à comunidade usuária da Libras a partir do contato com o design thinking, uma abordagem criativa, inovadora e colaborativa. Considera-se que o contato entre essas línguas pode ser um ponto de partida para promoção da interação entre surdos e ouvintes.

Palavras-chave: Língua Brasileira de Sinais; Língua minoritária; Ensino de língua materna.

Title: When the Portuguese language visits Libras: exploring design thinking and contact between languages in high school

Abstract: This article is a cutout of a master's research developed by lldebrand (2020). It seeks to describe and present a teaching action conceived in mother-tongue classes, by high school students, in a school located in the metropolitan region of Porto Alegre. Thus, in the Portuguese Language classes (majority language) space was provided and the Brazilian Sign Language (Libras) (minority language) was valued. Students and teachers were mobilized to outline solutions to problems related to the community using Libras, from the contact with design thinking, a creative, innovative and collaborative approach. It is considered that contact between these languages can be a starting point for promoting interaction between deaf and non-deaf.

Keywords: Brazilian Sign Language; Minority language; Mother language teaching.

\footnotetext{
${ }^{1}$ Mestre em Linguística Aplicada pela Universidade do Vale do Rio dos Sinos (UNISINOS). Professor Mediador do Instituto Nacional de Educação de Surdos no polo da UFRGS (INES/UFRGS). Orcid: https://orcid.org/0000-00022112-0656. E-mail: isaias.brand@hotmail.com.

${ }^{2}$ Doutora em Letras pela Pontifícia Universidade Católica do Rio Grande do Sul (PUCRS). Docente da Universidade do Vale do Rio dos sinos (UNISINOS). Orcid: https://orcid.org/0000-0002-7777-7884. E-mail: catiafronza@gmail.com.

${ }^{3}$ Doutoranda em Linguística Aplicada pela Universidade do Vale do Rio dos Sinos (UNISINOS), Técnica em Assuntos Educacionais do Instituto Federal do Rio Grande do Sul (IFRS). Orcid: https://orcid.org/0000-0002-42844549. E-mail: simonewluiz@hotmail.com.
} 


\section{Considerações preliminares}

A Língua Brasileira de Sinais (Libras), entendida como uma língua minoritária, devido ao seu status político e social (ALTENHOFEN, 2013), vem ganhando espaços significativos nos contextos acadêmicos e digitais (SOUZA; BARCELOS, 2016; CORRÊA; CRUZ, 2019). Nesse sentido, a inclusão dessa língua viso-espacial nos mais diversos âmbitos precisa de atenção, porque, mesmo presente nos espaços digitais e nas universidades brasileiras como disciplina que compõe o currículo acadêmico (NASCIMENTO; SOFIATO, 2016; VERAS; BRAYNER, 2018), há concepções políticas, sociais, educacionais e, principalmente, linguísticas que precisam minimizar quadros excludentes dessa língua (MEULDER et al., 2019). Nesse cenário, entendese que a Linguística Aplicada (LA) voltada ao ensino de línguas tem fundamental importância para viabilizar contatos entre uma língua oral-auditiva (português) e uma língua viso-espacial (Libras) na realidade da Educação Básica.

O arcabouço teórico deste trabalho mostra que a Libras ainda carece de atenção da Linguística Aplicada, a fim de ganhar espaço nas mais diversas linhas de pesquisas em que essa área se faz presente. Pesquisadores como Neigrames et al. (2018) e Meulder et al. (2019) apontam que é comum as línguas orais-auditivas dominarem espaços das línguas de sinais, seja nas práticas de ensino, nos meios de comunicação, nas condições políticas, sociais e linguísticas. Convocar, portanto, a LA para trazer à tona uma alternativa a esse panorama é fundamental, porque ela pode amparar as perspectivas e estudos às línguas de sinais (CELANI, 1998; 2000; OLIVEIRA, 2009; COOK, 2015; OSTERMANN; GUIMARÃES, 2019). Ao encontro dessas ideias, é preciso dar voz às línguas de sinais.

Posto isso, o objetivo deste artigo é apresentar uma ação desenvolvida junto à Educação Básica, em especial no Ensino Médio, capaz de valorizar a Libras, ou seja, tornar esta língua minoritária acessível e conhecida, neste caso, a alunos da Educação Básica ${ }^{4}$. Nesse sentido, duas perguntas ocupam espaço nesta discussão: (i) como promover acesso às línguas minoritárias no processo de ensino e aprendizagem de língua materna de alunos ouvintes do Ensino Médio?; (ii) é possível ouvintes aprenderem sobre uma língua viso-espacial em sala de aula nas perspectivas da Educação Básica?

Desse modo, uma experiência com o uso da abordagem design thinking (BROWN; WYAAT, 2010) se fez pertinente e capaz de consolidar uma prática de ensino e de aprendizagem voltada à resolução de problemas que, na proposta, voltou-se em observar processos de acessibilidade à comunidade surda, a fim de delimitar problemas e apresentar soluções robustas aos problemas evidenciados. O contato com o design thinking foi capaz de envolver os alunos a partir do desafio de pensar na acessibilidade aos surdos, bem como oportunizar espaço a uma língua tão presente no Brasil, mas que é pouco conhecida e, muitas vezes, não é entendida como língua (QUADROS; KARNOPP, 2004; LACERDA; GÓES, 2000). Não há dúvidas de que a escola tem papel transformador no percurso de desenvolvimento escolar

\footnotetext{
${ }^{4}$ Tal perspectiva tem como base dados gerados pela pesquisa de Mestrado desenvolvida por Ildebrand (2020).
} 
dos alunos. A proposta, desenvolvida com os discentes do Ensino Médio, caminha para descontruir o apagamento da Libras na sociedade e fortalecer os espaços que essa língua pode ocupar.

Tem-se como ponto de partida o entendimento de que as aulas de língua materna na escola dos ouvintes são capazes de incluir uma língua de sinais, de forma que essa inclusão é capaz de refinar os conhecimentos linguísticos dos alunos, como também mobilizar os (possíveis) envolvimentos entre surdos e ouvintes.

Com base nessas considerações, na próxima seção, é apresentado o arcabouço teórico da pesquisa, que reflete sobre a Linguística Aplicada e sua inserção/contribuição no/para universo das línguas orais e de sinais. Na sequência, trazem-se informações sobre o percurso metodológico da pesquisa que serve de mote para este artigo, com destaque para algumas das atividades realizadas e para a explicitação da abordagem design thinking, adotada como forma de pensar sobre as resoluções de problemas enfrentados pela comunidade surda. $\mathrm{Na}$ continuidade do artigo, discute-se sobre esses dados e as ressalvas ao final do trabalho quanto à implicação dessa abordagem nas aulas de língua materna.

\section{Pressupostos teóricos: Língua Brasileira de Sinais, inclusão e interdisciplinaridade}

Os caminhos que a Linguística Aplicada (LA) vem percorrendo mostram, cada vez mais, a sua importância nas perspectivas inclusivas e interdisciplinares (CELANI, 1992; 1998; 2000; KLEIMAN, 1998; OLIVEIRA, 2009; OSTERMANN; GUIMARÃES, 2019). Essa demanda está cada vez mais presente em pesquisas e trabalhos acadêmicos onde emerge $(\mathrm{m})$ a (s) língua(s) e a linguagem (SOUZA; BARCELOS, 2016). Estando a LA integrada a uma "visão pluri/multi/interdisciplinar" (CELANI, 1998, p. 132), a capacidade em identificá-la nas mais diferentes abordagens de pesquisa tem sido evidenciada pelos estudos contemporâneos na área, explanando as diversidades existentes sobre o uso da linguagem e os olhares futuros que ela precisa assumir (COOK, 2015). Poder pensar em perspectivas inclusivas e interdisciplinares é recorrer a uma linguística pluri/multi/interdisciplinar, mostrando sua preocupação, também, com as línguas de sinais. Consolidar o reconhecimento da LA em toda(s) a(s) modalidade(s) da(s) língua(s) (GROSJEAN, 1994a; 1994b) legitima, portanto, a equidade dessa área científica nos mais diversos modos em que se manifestam a(s) língua(s) no mundo.

Entretanto, tal visão pode não se aplicar às línguas minoritárias (ALTENHOFEN, 2013; MEULDER et al., 2019) nessa ótica em que as línguas de modalidade viso-espacial (GROSJEAN, 1994a; 1994b) se encontram. Um exemplo claro decorre da e sobre a Libras. Nesse sentido, recorre-se aos estudos de Lacerda e Góes (2000) que discutem as subjetividades presentes no universo da surdez. Uma dessas subjetividades se estabelece sobre a língua de sinais, pois a pessoa surda, em seu desenvolvimento social e escolar, vive à mercê da língua majoritária, que, nesse caso, é a língua de modalidade oral-auditiva. 
Os status políticos e sociais são termos pertinentes para entender o conceito de língua minoritária, como advoga Altenhofen (2013). Para esse autor, compreende-se que as línguas minoritárias são aquelas variedades ou modalidades usadas à margem ou adjacentes às línguas dominantes, como é o caso da Libras, língua de modalidade viso-espacial, por vezes confundida como uma reprodução visual da língua portuguesa no Brasil, língua majoritária, de uso comum da comunidade ouvinte (QUADROS, 1997; LACERDA; GÓES, 2000). Mesmo com a promulgação da Lei $n$ o 10.436/2002 (BRASIL, 2002), valorizando a Libras nas perspectivas da Educação Brasileira, ainda há políticas públicas que não levam em conta as diferenças linguísticas e culturais dos surdos. Em adição a isso, algumas interpretações generalizadas da Libras podem interferir e causar uma imagem negativa ou inferiorizada da pessoa surda (LACERDA; GÓES, 2000; SILVA, 2015). É importante esclarecer que a apropriação da língua portuguesa na modalidade escrita pelo surdo não é uma tarefa simples, pois este, na grande maioria dos casos, não é usuário de uma língua oral-auditiva. Contudo, alguns surdos não só aprendem, mas também se utilizam da língua portuguesa em situações interacionais com os ouvintes.

Diante da realidade contextual dos surdos, pode-se dizer que as experiências linguísticas são muito mais abrangentes para as culturas ouvintes (QUADROS, 1997; GESSER, 2009; 2012). Meulder et al. (2019) e Silva (2015) apontam que é comum línguas orais-auditivas dominarem, até mesmo, as línguas viso-espaciais. Um exemplo claro são os cinemas, espaços sociais que priorizam línguas orais, excluindo língua(s) de sinais, afastando também os usuários dessa língua desses espaços sociais. Vale destacar que a legenda é construto das línguas orais e nem todos os surdos conhecem ou dominam as convenções em determinadas produções cinematográficas. Essa proposição pode ser claramente interpretada sobre os contextos da LA, a qual ainda enfrenta obstáculos para incluir línguas minoritárias nos mais diversos espaços, como é o caso da Libras, que ainda precisa se inserir em determinados contextos para contemplar as necessidades comunicacionais das pessoas surdas (GESSER, 2009; 2012; SOUZA; BARCELOS, 2016; MEULDER et al., 2019).

Souza e Barcelos (2016) destacam que trabalhos no campo da LA, trazendo à tona a Libras, já ganham evidência no cenário atual. No entanto, há olhares ainda escassos no que diz respeito às linhas de pesquisa específicas, como análise da conversa, ensino de línguas para fins específicos, linguagem e literatura, trabalho e linguagem, entre outros. Além disso, o ensino de Libras a grupos majoritários, neste caso os ouvintes, ainda carece de práticas e propostas de ensino e aprendizagem a esse público (PEREIRA, 2009; NASCIMENTO; SOFIATO, 2016; VERAS; BRAYNER, 2018). Mesmo com a inserção da Libras nas instituições universitárias, Nascimento e Sofiato (2016) e Veras e Brayner (2018) destacam que a disciplina de Libras na academia não contempla o que se espera pela legislação, que é formar profissionais que conheçam conceitos sobre a pessoa surda, surdez e a Libras, e recebe pouco espaço nos campos da pesquisa em ensino de língua(s), tornando cada vez mais difícil a sua afirmação e efetivação sobre e nas ações de ensino e aprendizagem da Libras nas Instituições de Ensino Superior (IES). 
O ensino de Libras nas IES é recente. A partir de sua oficialização em 2005 (BRASIL, 2005), por meio do Decreto no 5.626/2005, tornando-se disciplina obrigatória ${ }^{5}$ nos cursos de licenciatura e fonoaudiologia, suas concepções vêm sendo tensionadas em estudos como os de Brito et al. (2013), Nascimento e Sofiato (2016), Veras e Brayner (2018), que apontam lacunas para o cumprimento dessa legislação. São escassos os relatos de experiência nesse contexto, os quais poderiam contribuir para se pensar a inserção e as práticas de ensino dessa disciplina na academia, para fortalecer os currículos da disciplina ou os cursos de Libras (SANTOS, 2015; NASCIMENTO; SOFIATO, 2016). Nesses estudos, certas variáveis entram em contexto, como a carga horária destinada ou a oferta de apenas uma disciplina ao longo do curso. Como destacam Santos (2015), Nascimento e Sofiato (2016), tais alternativas não possibilitam alcançar o conhecimento e aprendizagem de uma língua.

Tais apontamentos iniciais permitem entender que a não efetivação do que determina a legislação reflete as condições de vida das pessoas surdas (MARTINS, 2008; GESSER, 2012; MEULDER et al., 2019). Uma vez que, nos cursos de nível superior, a aprendizagem dessa língua vem reverberando espaços a serem caucionados, é prudente identificar o que pode favorecer e subsidiar um ensino e uma aprendizagem olhando, principalmente, para a competência linguístico-comunicativa (GESSER, 2012; VERAS; BRAYNER, 2018; NEIGRAMES et al., 2018), minimizando as implicações para integrar e favorecer espaços a essa língua minoritária e fortalecendo possíveis interações entre surdos e ouvintes. Assim sendo, a LA pode advogar em prol da Libras, das problemáticas que evocam dos processos de ensino e aprendizagem e dos fenômenos culturais que a cercam (NEIGRAMES et al., 2018), equiparando-se ao que Meulder et al. (2019) revelam a partir da compreensão de que as resoluções culturais, linguísticas, políticas e sociais são espaços de privilégios para ouvintes.

Nesse construto, cabe recorrer a um tema de interesse da LA que possui vasto caminho teórico: o ensino de línguas. Ganhando evidência na década de 1940, a gênese da LA surgiu como uma forma de aplicar a Linguística Tradicional a fim de desenvolver métodos e metodologias capazes de efetivar o ensino e a aprendizagem de línguas (CELANI, 1992; 1998; 2000; KLEIMAN, 1998). Sendo a LA provocada a fim de descrever e desvendar fenômenos e solucionar problemas do mundo real, evocados a partir da linguagem, tendo a contínua preocupação com os processos de ensino e aprendizagem de língua(s) (CELANI, 2000; NEIGRAMES et al., 2018), precisa-se caminhar com a LA também nos contextos sociais, políticos, culturais e interacionais onde se encontra $(m)$ a(s) língua(s) de sinais, legitimando sua real perspectiva inclusiva e interdisciplinar, que ainda carece de estudos (OLIVEIRA, 2009; GESSER, 2012; ALTENHOFEN, 2013; SOUZA; BARCELOS, 2016). A educação de surdos tem grande âmago nos estudos da Libras e da língua portuguesa, sendo mais uma frente da LA que se empreende no Brasil (OSTERMANN; GUIMARÃES, 2019).

A LA pode contribuir para a construção de caminhos efetivos para oportunizar espaço à Libras (OSTERMANN; GUIMARÃES, 2019), tanto nas perspectivas de ensino e aprendizagem

\footnotetext{
${ }^{5} \mathrm{Em}$ alguns casos, a disciplina é optativa, como acontece nos cursos para tecnólogos e nos bacharelados.
} 
quanto nos espaços que os surdos frequentam e podem ocupar. Logo, recorrendo à LA e ao ensino de língua(s), é cabível apontar dois questionamentos neste artigo: a) como promover o acesso às línguas minoritárias no processo de ensino e aprendizagem de língua materna de alunos ouvintes do Ensino Médio? e b) é possível ouvintes aprenderem sobre um língua visoespacial na sala de aula nas perspectivas da Educação Básica?

Na seção a seguir, apresentaremos uma proposta de tarefa com foco na Libras e na Cultura Surda, realizada com um grupo de alunos do Ensino Médio de uma escola pública, durante a pesquisa de mestrado de Ildebrand (2020). Pelas restrições de espaço e temática desta publicação, registram-se alguns momentos do trabalho desenvolvido, com vistas a promover esta língua minoritária presente na vida de milhões de brasileiros surdos, a Libras.

\section{A Libras nas aulas de Língua Portuguesa: caminhos metodológicos e apresentação dos dados gerados}

De caráter qualitativo e exploratório (STAKE, 2011; LUDKE; ANDRE, 2013), o recorte da pesquisa de lldebrand (2020), apresentado neste artigo, explora uma proposta de tarefa sobre acessibilidade aos surdos e Libras no escopo das aulas de língua materna de alunos ouvintes. O ensino de Libras, na maior parte dos contextos com que o aluno ouvinte tem contato, não atende ao determinado pelas políticas vigentes no Ensino Superior (BRASIL, 2005), devido a inúmeros fatos (BRITO et al., 2013; NASCIMENTO; SOFIATO, 2016; VERAS; BRAYNER, 2018), indicados na seção de revisão teórica deste artigo. Assim, vale envolver alunos ouvintes do Ensino Médio com conhecimentos e informações sobre a Libras e a cultura surda, a fim de minimizar quadros de exclusão dessa língua viso-espacial, entendendo que as aulas de Língua Portuguesa são capazes de se constituírem como um espaço de aprendizagens e discussão a respeito do status da Libras e, principalmente, dos que a utilizam (ou se espera que o façam) em seu percurso comunicacional.

Como resposta a essa demanda, foi desenvolvido um projeto de ensino nas aulas de língua materna de duas turmas de alunos ouvintes do 3 ano do Ensino Médio de uma escola pública localizada na região metropolitana de Porto Alegre. O professor da disciplina de Língua Portuguesa também atua como Tradutor e Intérprete de Língua Brasileira de Sinais. A metodologia utilizada para ensino fundamenta-se na Aprendizagem Baseada em Resolução de Problemas (ABRP) (MAMEDE; PENAFORTE, 2001; SCHMIDT, 2001) que, a partir de um conjunto de abordagens e recursos de conhecimento e informação apresentados pelo professor, convergem para o discente pensar em resoluções para problemas das mais diversas amplitudes.

A seção seguinte apresenta alguns detalhes do estudo desenvolvido para o entendimento do contexto e dos desdobramentos das discussões instigadas por lldebrand (2020). 
Cenário da pesquisa: a escola e os participantes

Antes de falar da tarefa com foco na Libras e envolvendo a ABRP, é necessário contextualizar o cenário ao qual este texto se remete. Como já foi mencionado, este trabalho se constituiu com base na pesquisa de mestrado de lldebrand (2020), aprovada pelo Comitê de Ética da Unisinos, conforme CAAAE 02429918.0.0000.5344.

A geração de dados ocorreu durante aulas de Língua Portuguesa no primeiro semestre de 2019, ao longo de 20 horas/aula, ministradas pelo primeiro autor deste artigo. Todos os encontros estão registrados em vídeo, e os dados foram considerados pela lente de estudos que têm como objeto língua, linguagem e ensino. Participaram da pesquisa 47 alunos de duas turmas do 30 ano do Ensino Médio de uma escola estadual do Rio Grande do Sul. A Instituição Escolar, na qual o projeto de pesquisa foi desenvolvido, conta com as etapas de ensino da Educação Básica de nível Fundamental a Médio, contemplando uma realidade à parte da maioria das escolas estaduais, pois é um espaço equipado com recursos didáticos para fins educacionais e conta com quadro de professores e funcionários completo.

Durante o desenvolvimento do projeto, nas 20 horas-aula da disciplina de língua portuguesa, emergiram concepções, conhecimentos e informações sobre a Libras e a Cultura Surda. Ocorreram momentos de comparações entre as línguas majoritárias (orais-auditivas) e as línguas minoritárias (viso-espaciais), quando, por exemplo, o professor conduziu uma comparação entre as estruturas linguísticas da língua portuguesa e da Libras, oportunizando aos alunos entenderem que a Libras é tão complexa e natural como o Português (QUADROS, 1997; GROSJEAN, 1994a; 1994b; BRITO, 1984; BRITO et al., 2013; GESSER, 2009; SILVA, 2015). Aulas específicas voltadas ao uso da Libras em saudações, dias da semana, conhecimento do alfabeto manual da Libras foram evocadas nesse contexto de ensino e de aprendizagem. Além disso, vale destacar que os participantes tiveram envolvimento com a Libras, com sinalização de nível básico, acessaram recursos utilizados na e pela comunidade surda, como aplicativos e dicionários virtuais em Libras, selecionados e ofertados pelo docente durante as aulas.

Os alunos também tiveram a oportunidade de definir um sinal em Libras para representar seus nomes, estratégia comum na comunidade surda, indicada como batismo ${ }^{6}$. As experiências e envolvimentos do professor e dos alunos foram contextualizadas. Em adição a isso, evidenciou-se que alguns alunos conheciam pessoas surdas e o alfabeto manual.

Após essa contextualização, será enfatizado, na seção seguinte, o trabalho desenvolvido por meio do design thinking durante 4 das 20 aulas de língua portuguesa, conforme registra lldebrand (2020).

\footnotetext{
${ }^{6}$ Quando uma pessoa recebe um sinal para que seu nome seja representado na língua da comunidade surda, como se fosse seu substantivo próprio, seu nome, sinalizado e não falado ou escrito.
} 
Uma tarefa inovadora: abordagem do design thinking como proposta de ensino com foco na Libras e Cultura Surda

Como já anunciado, nesta seção, destaca-se a concepção inovadora de tarefas por meio da abordagem design thinking (ILDEBRAND, 2020). A escolha pelo design thinking como tarefa a ser realizada pelos alunos se tornou pertinente, pois a metodologia denominada Aprendizagem Baseada na Resolução de Problemas está alinhada à necessidade de resolver problemas (MAMEDE; PENAFORTE, 2001; SCHMIDT, 2001), no contexto da referida pesquisa. As fases e o processo desenvolvidos a partir do design thinking geraram etapas pertinentes para propor soluções aos problemas evidenciados e identificados pelos alunos ouvintes sobre adversidades enfrentadas pelas pessoas com surdez no Brasil. Isso vai ao encontro do que Brown e Wyaat (2010) apontam como contribuição do design thinking: inovar para resolver problemas. Mello (2014) e Spagnolo (2017) consideram o design thinking como ferramenta de trabalho do professor, oportuna em uma educação contemporânea, envolvendo problemáticas presentes no cotidiano das pessoas. Os autores afirmam que, para pensar em soluções, é preciso seguir etapas com o intuito de propor uma alternativa eficaz ao problema evidenciado.

Na Figura 1, é possível identificar um fluxograma com as etapas do design thinking, evidenciando o processo de estudos percorrido pelos alunos. No Quadro 1, por sua vez, é possível identificar as tarefas realizadas em aula a partir da ação dos alunos.

Figura 1 - Fluxograma das fases na metodologia Design Thinking com base em Brown, Wyaat (2010), Mello (2014) e Spagnolo (2017)
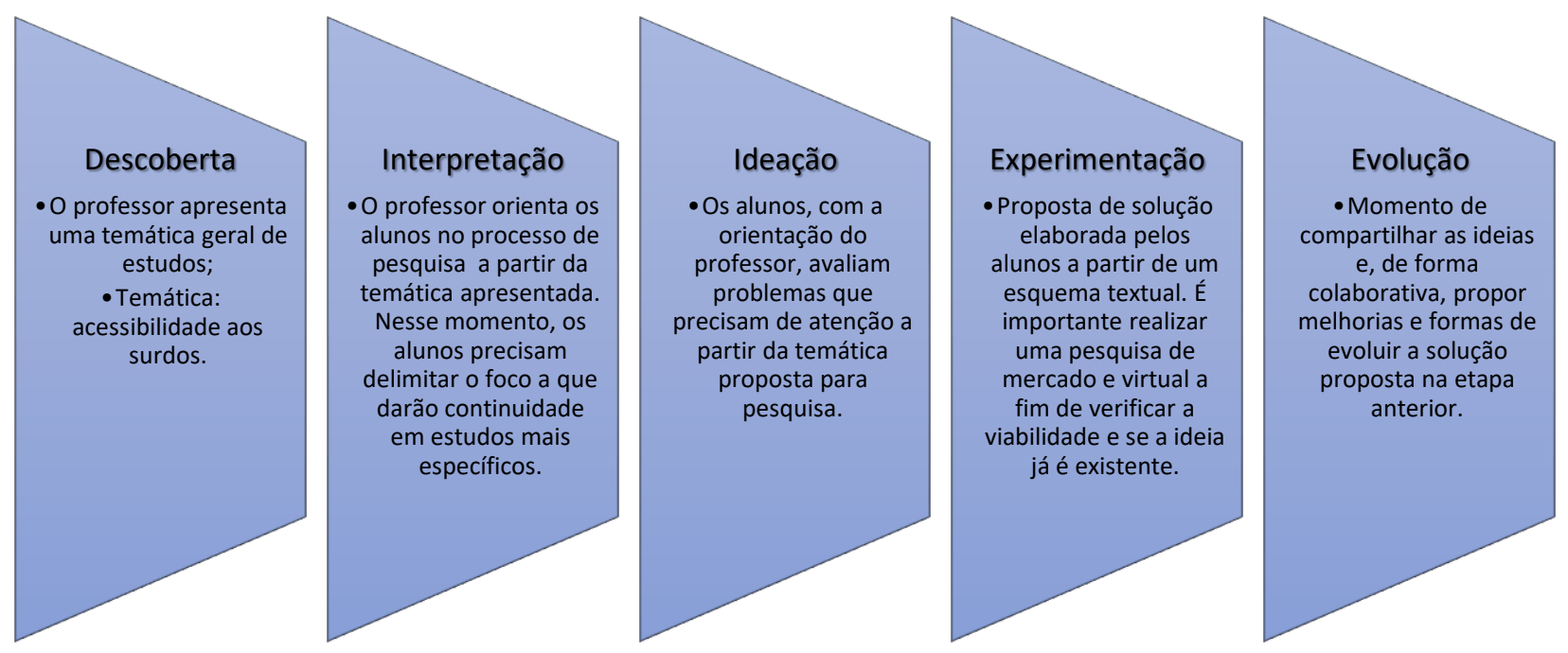

Fonte: Elaborada pelos autores. 
Quadro 1 - Tarefa e etapas desenvolvidas pelos alunos durante as aulas

\begin{tabular}{|l|l|}
\hline \multicolumn{1}{|c|}{ TARESES } & \multicolumn{1}{c|}{ DESCRIÇÃO BREVE DAS AÇÕES REALIZADAS EM CADA TAREFA } \\
\hline Descoberta & $\begin{array}{l}\text { Os alunos foram desafiados a pensar sobre } \text { a acessibilidade aos surdos nos diversos espaços } \\
\text { sociais. }\end{array}$ \\
\hline Interpretação & $\begin{array}{l}\text { Os alunos organizaram-se em pequenos grupos e foram ao laboratório de informática da } \\
\text { escola e fizeram uma pesquisa orientada pelo professor, a fim de conhecer mais sobre o } \\
\text { universo da comunidade surda. A partir da pesquisa, selecionaram perguntas e curiosidades } \\
\text { a fim de aprofundar os estudos sobre essa seleção efetivada. }\end{array}$ \\
\hline Ideação & $\begin{array}{l}\text { Os estudos realizados foram vetores para encontrar problemáticas que necessitam de } \\
\text { solução. }\end{array}$ \\
\hline Experimentação & $\begin{array}{l}\text { Os alunos pensaram em soluções para os problemas delimitados e construíram um esquema } \\
\text { textual para evidenciar essa solução. }\end{array}$ \\
\hline Evolução & $\begin{array}{l}\text { O professor conduziu um seminário a fim de compartilhar as proposições realizadas pelos } \\
\text { alunos. Tanto professor quanto alunos contribuíram para evolução das soluções apresentadas } \\
\text { no momento do seminário. }\end{array}$ \\
\hline
\end{tabular}

Fonte: Elaborado pelos autores.

Na Figura 1 e no Quadro 1, identificam-se as etapas de cada momento da tarefa. $\mathrm{Na}$ etapa da descoberta, o professor apresentou um tema geral que, na ocasião, foi sobre a acessibilidade aos surdos. Por se tratar de um tema geral, os alunos, no momento da etapa da interpretação, conforme apresenta Ildebrand (2020), afunilaram o conceito de acessibilidade, se dedicando a um contexto específico, como acessibilidade urbana, acessibilidade linguística, acessibilidade educacional e acessibilidade de informação. Em seguida, na etapa da ideação, mapearam problemas nesses estudos a partir da pesquisa realizada no laboratório de informática da Escola. Identificado um problema, foi a vez de pensar em uma solução ou alternativa para amenizar a inacessibilidade às pessoas com surdez. Portanto, a etapa da evolução, o ciclo final da tarefa, culminou em um seminário, a fim de professor e alunos contribuírem, qualificarem e, de certo modo, evoluírem a ideia pensada.

Na sequência, considera-se, então, a atividade que receberá atenção neste artigo.

Produções realizadas pelos alunos: a resolução de problemas e as etapas do design thinking

Nesta parte do artigo, dá-se visibilidade à produção de um esquema textual esboçando uma proposta de recurso tecnológico por parte de um dos grupos de alunos. Uma vez que este estudo destaca os esforços da LA a contemplar e perfazer soluções nos contextos em que se estabelecem as línguas, na proposta evocada pelos discentes é possível ver uma resolução de problemas que convoca a língua e a linguagem. Para tanto, outros protótipos e resoluções de problemas foram elaborados por outros discentes. Neste momento, destaca-se a proposta "Watching The Music", pensada por um grupo de alunos devido a seu caráter, entendido, portanto, como um recurso possível de oportunizar acessibilidade linguística à surdos e ouvintes no quesito da Libras. É pertinente considerar que as outras produções podem servir 
de ponte para trabalhos futuros, explorando ainda mais as produções realizadas pelos alunos nas aulas de língua materna.

Embora o trabalho tenha tido como foco a cultura surda e a Libras, não se exige do professor o domínio da Libras para o uso da metodologia que está em foco, já que ensinar e aprender uma língua requer um percurso extenso de formação. O objetivo desta reflexão é desencadear o campo das ideias, pensar em formas e soluções que extrapolem a imaginação, numa perspectiva inclusiva, oportunizando espaço à Libras na sala de aula.

A intenção das pesquisas qualitativas se estabelece no processo de entender o comportamento e as produções feitas em pequenos grupos e os detalhes dos dados coletados (STAKE, 2011; LUDKE; ANDRÉ, 2013). Sob essa perspectiva, o Quadro 2 representa o processo de busca e descobertas realizadas pelo grupo a partir das etapas do design thinking.

\begin{tabular}{|l|l|}
\multicolumn{2}{|c|}{ Quadro 2 - Caminhos realizados pelo grupo: proposta “Watching The Music" } \\
\hline \multicolumn{1}{|c|}{ FASES } & \multicolumn{1}{c|}{ DESCRIÇÃo BREVE DAS AÇÕES REALIZADAS PELOS ALUNOS DO GRUPO } \\
\hline Descoberta & $\begin{array}{l}\text { Os alunos pesquisaram e identificaram que há surdos que apreciam conteúdo musical nas } \\
\text { línguas de sinais, em especial, os sinalizantes da Libras. }\end{array}$ \\
\hline Interpretação & $\begin{array}{l}\text { Os alunos, com a orientação do professor, pesquisaram sobre tradução e música na Libras. } \\
\text { Ocorreram relatos de que gostavam de aprender outras línguas através de músicas. }\end{array}$ \\
\hline Ideação & $\begin{array}{l}\text { Os alunos identificaram um problema. Há muitas plataformas que comportam músicas em } \\
\text { línguas orais, que é o caso do Spotify }{ }^{T} \text {. Por que não propor uma plataforma que comporte } \\
\text { músicas em Libras? }\end{array}$ \\
\hline Experimentação & $\begin{array}{l}\text { Os alunos propuseram uma plataforma nomeada “Watching The Music", que estabelece } \\
\text { maneiras de reprodução de músicas sinalizadas e traduzidas para surdos e ouvintes. }\end{array}$ \\
\hline Evolução & $\begin{array}{l}\text { O professor conduziu um seminário a fim de compartilhar as proposições realizadas pelos } \\
\text { alunos. Tanto o professor quanto os alunos contribuíram para a evolução das soluções } \\
\text { apresentadas no momento do seminário. }\end{array}$ \\
\hline
\end{tabular}

Fonte: Elaborado pelos autores.

Na busca por informações da pesquisa realizada pelos alunos, etapa da interpretação da abordagem design thinking, eles identificaram em vídeos e leituras virtuais que havia um grupo na comunidade surda que possui afeição pela poesia e pela música ou tradução de músicas em Libras. À medida que a busca era realizada, os discentes registravam o que consideravam relevante em seus cadernos. Nessa busca, descobriram que, para pessoas ouvintes, há inúmeros recursos, plataformas e aplicativos, porém não há recursos semelhantes com esse tipo de conteúdo à disposição de pessoas que queriam consumir músicas sinalizadas em Libras ou músicas traduzidas do português para a Libras. O problema evidenciado retoma a etapa da ideação. Posto isso, a solução para ofertar esse tipo de conteúdo a esse grupo de surdos que aprecia música seria uma plataforma (ou possível aplicativo) capaz de comportar esse tipo de conteúdo.

O Quadro 2, portanto, mostrou o processo pelo qual foi planejada a plataforma por esse grupo de alunos. Na Figura 2, é possível acompanhar a produção do esquema textual 
elaborado pelo grupo de alunos. Destaca-se que não há intervenções no material elaborado pelo grupo, devido à importância da naturalidade do dado.

Figura 2 - Produção e proposta de solução elaborada por um grupo de alunos da turma de 3o ano do Ensino Médio

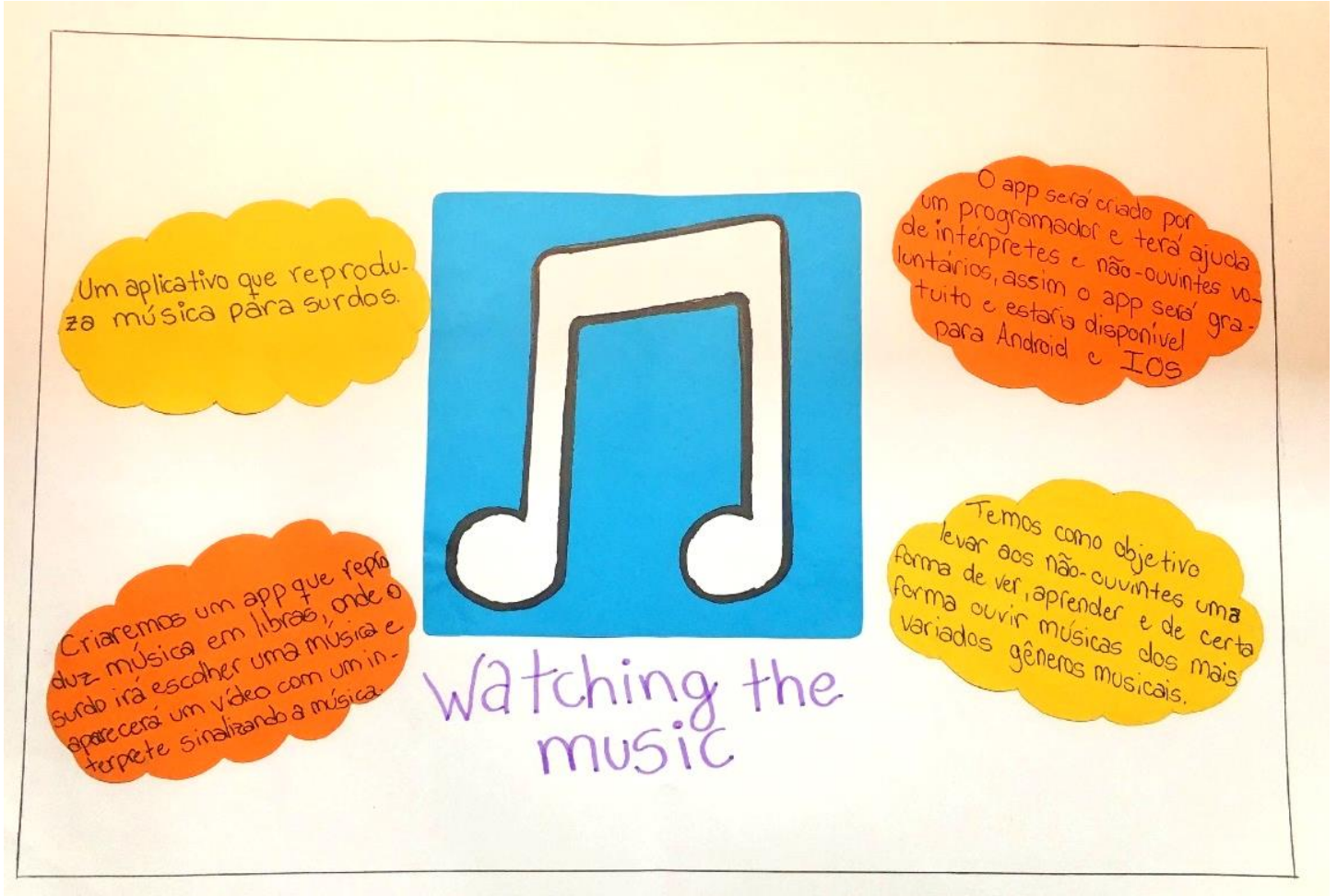

Fonte: Acervo da pesquisa de Ildebrand (2020, p. 125).

A abordagem com o design thinking na aula corroborou com o processo de escrita e de leitura. Mesmo com essa abordagem considerada inovadora na aula de Português, as habilidades e competências sobre esses processos continuaram e se fizeram presentes no percurso de ensino e de aprendizagem. Tem-se, assim, uma abordagem capaz de continuar a envolver o alunado com o universo da escrita e da leitura. Segue-se, portanto, para as discussões sobre a tarefa e as mobilizações decorrentes da proposta.

\section{O espaço à Libras nas aulas de língua materna dos ouvintes: discussão sobre percursos que valorizam a Libras nos espaços sociais}

A tarefa proposta com uso do design thinking mostrou que é possível pensar em soluções a fim de valorizar a Libras nos mais diversos cenários. O produto criado pelo grupo de alunos, "Watching The Music", exemplifica um dos espaços que a Libras ainda pode ocupar. Nesse sentido, Quadros (1997), Silva (2015) e Meulder et al. (2019) destacam que é comum as línguas orais dominarem até mesmo as línguas de sinais. O problema que os alunos apontaram mostra, nas perspectivas tecnológicas, que poucos desses recursos são pensados para o consumo desse tipo de conteúdo pela comunidade surda, mostrando como a língua 
oral tem privilégio em relação à língua de sinais. Vê-se, nesse sentido, potencial para a LA, já que as aulas de língua portuguesa foram um vetor para valorizar e dar espaço à Libras e pensar nos contextos de dominância da majoritária no Brasil.

A metodologia de ensino voltada à ABRP (MAMEDE; PENAFORTE, 2001; SCHMIDT, 2001) propõe que o professor conduza conhecimentos suficientes e, a partir disso, desafie os alunos com problemáticas diversas com o intuito de solucionar esses problemas, como se observa no relato de experiência em relação ao trabalho do professor. Em uma das aulas, a acessibilidade aos surdos foi considerada um problema a resolver pelos próprios alunos, mediante suas pesquisas durante o percurso na etapa de interpretação do design thinking. 0 professor e seus alunos foram mobilizados a compartilharem suas experiências com a comunidade surda, uma etapa importante para complementar a metodologia ABRP utilizada pelo docente.

Além de o design thinking ser um processo metodológico inovador para pensar em soluções (BROWN; WYAAT, 2010; MELLO, 2014; SPAGNOLO, 2017), também se caracterizou como abordagem para a aprendizagem dos alunos, já que eles realizaram e seguiram cada etapa a fim de encontrar uma solução aos problemas desvendados nas pesquisas no laboratório de informática na escola. Dessa forma, a proposta pensada pelo grupo "Watching The Music" caracteriza o percurso de estudos desses discentes, porque o professor apresentou um problema, eles mapearam uma temática para estudar, encontraram uma lacuna no acesso a músicas sinalizadas e propuseram a ideia da plataforma, a fim de potencializar os espaços da Libras.

Essa ideia, desencadeada pelos alunos na aula de língua portuguesa, pode gerar interpretações e entendimentos nas mais diversas áreas. Tratando-se da LA, que é a área capaz de concentrar o contexto do Ensino de Línguas, e deste estudo realizado com os estudantes do Ensino Médio, compreende-se que as aulas de língua materna de ouvintes brasileiros também é um lugar para uma língua minoritária como a Libras (BRITO, 1984; CELANI, 1998; CELANI, 2000; CALVET, 2007; ILDEBRAND, 2020). Dessa forma, como resposta às perguntas que nortearam este artigo em relação à forma de promover acesso a uma língua minoritária como a Libras, garantindo sua aprendizagem em aula de língua portuguesa, a tarefa com o design thinking mostrou-se relevante no processo de ensino e de aprendizagem da língua materna de alunos ouvintes do 3 ano do Ensino Médio, revelando que pensar na língua extrapola as concepções tradicionais, trazendo à tona outras abordagens para além da gramática (CELANI, 1992; PEREIRA, 2009). Os resultados discutidos no escopo deste trabalho evidenciaram a vivência muito bem-vinda no espaço de escolarização de estudantes ouvintes do Ensino Médio de uma forma criativa e colaborativa, onde professor e alunos mobilizaram esforços para propor soluções a problemas reais vivenciados pela comunidade surda. Em adição a isso, é possível pensar e construir aprendizagens a partir de metodologias e objetos de estudos que concentram diferentes línguas e linguagens. Esses alunos ouvintes aprenderam sobre uma língua viso-espacial no contexto da Educação Básica. Nesse sentido, entende-se que esse pode ser um ponto de partida para estudos futuros, potencializando as 
(possíveis) interações entre surdos e ouvintes (GESSER, 2009; 2012), bem como os envolvimentos futuros desses alunos com a Libras nos diversos espaços sociais, nos quais também está o contexto acadêmico (BRITO et al., 2013; NASCIMENTO; SOFIATO, 2016; VERAS; BRAYNER, 2018; MARTINS, 2008).

Retorna-se ao arcabouço teórico da LA, em que sua "visão pluri/multi/interdisciplinar" (CELANI, 1998, p. 132) ganha voz neste estudo, pois concentrou-se no ensino de línguas, neste caso, a língua portuguesa, como capaz de dar lugar e valorizar a Libras nas aulas da Educação Básica, utilizando a metodologia ABRP como abordagem de ensino adotada pelo professor, e o design thinking, como tarefa e abordagem de estudos experienciadas pelos alunos. É nesse sentido que se concorda com o estudo de Cook (2015), evidenciando que a LA precisa avançar e traçar novos horizontes. Temos, então, uma LA envolvida com métodos e metodologias atuais que podem comportar as práticas de ensino e de aprendizagem da língua portuguesa, mas trazendo novos objetos a serem explorados nas aulas (OSTERMANN; GUIMARÃES, 2019) como o caso da Libras e do design thinking (ILDEBRAND, 2020).

Nos aspectos gerais deste artigo, foi possível acompanhar discussões e estudos destacando as concepções de línguas minoritárias (ALTENHOFEN, 2013; MEULDER et al., 2019), especialmente a língua de sinais brasileira. No Brasil, a Libras cada vez mais vem construindo seu legado, seja na LA (QUADROS, 1997; SOUZA; BARCELOS, 2016; OSTERMANN; GUIMARÃES, 2019) ou nas práticas de instituições educacionais em que se evocam a aprendizagem e ensino de uma ou mais línguas (NEIGRAMES et al., 2018; NASCIMENTO; SOFIATO, 2016; PEREIRA, 2009; SILVA, 2015). Mesmo a Libras estando, por vezes, à margem do Português, é possível colocá-la em contato nas aulas dos ouvintes, ressignificando os objetos de estudos nas aulas de língua materna, valorizando o idioma utilizado por grande parte da comunidade surda e pensando em soluções para problemas reais nos contextos onde emergem a(s) língua(s) e a linguagem.

\section{Considerações finais}

Para o professor (em trabalho ou formação), esta proposta pode ser um ponto de partida para inserir uma língua minoritária (Libras) nas aulas de língua majoritária (Português) de alunos matriculados nas escolas brasileiras. Nesse sentido, a pesquisa descreve e não prescreve sua possível inserção na escola dos ouvintes, já que cada realidade é repleta de subjetividades (LACERDA; GÓES, 2000; MEULDER et al., 2019). Cabe, então, ao professor identificar e, achando pertinente, desenvolvê-la em seu enfoque com os alunos.

Conforme Ildebrand (2020), a Libras tornou-se objeto de estudo dos alunos a partir do uso do design thinking, abordagem que os desafiou a pensar em inovações para a comunidade surda. Nesse sentido, a aula de Português tornou-se um espaço capaz de legitimar o contato entre a Libras e o português, mobilizando a criatividade e a capacidade de pensar em soluções para problemas reais presentes sobre a língua e a linguagem. Uma vez que foi oportuno valorizar a Libras nas aulas de Português, vê-se o papel dos estudos em LA em advogar e 
conduzir caminhos para inserir línguas minoritárias nos processos de ensino e de aprendizagem.

Pensando nos cenários da aprendizagem e com o intuito de potencializar a proposta de tarefa, os alunos poderiam ter um espaço na escola dedicado à criação desses projetos. Uma alternativa é envolver o movimento maker, que tem por base a concepção de que pessoas comuns são capazes de construir, criar, consertar, adaptar e fabricar diferentes objetos e projetos com o apoio de recursos tecnológicos (DOUGHERTY, 2012). Cabe ao governo e instituições investirem nesses espaços e vigorarem o potencial que a escola e as aulas de língua materna têm.

Posto isso, é importante que os professores estejam a par das metodologias atuais de ensino, ofereçam espaço em suas aulas às línguas minoritárias por meio de projetos, tarefas e atividades capazes de lidar com essas e outras diversas situações que possam gerar aprendizagem e conhecimentos nas aulas de língua materna, evitando rótulos, preconceitos e exclusão. Essas ações podem ressignificar os contatos entre as línguas, rompendo com barreiras comunicacionais e sendo um vetor para contribuir com as (possíveis) interações entre surdos e ouvintes.

Ademais, o presente estudo sugere uma proposta de tarefa a fim de minimizar cenários que não contemplam os usuários das línguas de sinais, em especial, a Libras. Voltamos assim à tradição da LA mostrando que as aulas e os processos de ensino e de aprendizagem de língua(s) são espaços efetivos e oportunos que possibilitam práticas inclusivas e alternativas para garantir visibilidade à Libras e à aprendizagem.

\section{Referências}

ALTENHOFEN, C. V. Bases para uma política linguística das línguas minoritárias no Brasil. In: NICOLAIDES, C. et al. (Orgs.). Políticas e políticas linguísticas. Campinas: Pontes, 2013. p. 93116.

BRASIL. Decreto no 5.626, de 22 de dezembro de 2005. Regulamenta a Lei no 10.436, de 24 de abril de 2002, que dispõe sobre a Língua Brasileira de Sinais - Libras, e o art. 18 da Lei no 10.098, de 19 de dezembro de 2000. Brasília, 22 de dezembro de 2005, 184ㅇ da Independência e 117으 da República. Disponível em: <http://www.planalto.gov.br/ccivil03/_ato2 0042006/2005/decreto/d5626.htm>. Acesso em: 12 fev. 2020.

BRASIL. Lei no 10436, de 24 de abril de 2002. Dispõe sobre a Língua Brasileira de Sinais - Libras e dá outras providências. Brasília, 24 de abril de 2002, 181으 da Independência e 114으 da República. Disponível em:

<http://www6.senado.gov.br/legislacao/ListaPublicacoes.action?id=234606>. Acesso em: 12 fev. 2019.

BRITO, F. B. et al. O movimento surdo e sua luta pelo reconhecimento da Libras e pela construção de uma política linguística no Brasil. In: ALBRES, N. A.; NEVES, S. L. G. (Orgs.). Libras em estudo: política linguística. São Paulo: FENEIS, 2013. p. 67-103.

BRITO, L. F. Similarities \& differences in two Brazilian sign languages. Sign Language Studies, Washington, v. 42, n. 1, p. 45-56, 1984. https://doi.org/10.1353/sls.1984.0003 
BROWN, T.; WYAAT, J. Design thinking for social innovation. Stanford Social Innovation Review, v. 8, n. 1, 2010.

CALVET, L. J. As políticas linguísticas. São Paulo: Parábola Editorial, 2007.

CELANI, M. A. A. Afinal, o que é Linguística Aplicada? In: PASCHOAL, M. S. Z. Linguística Aplicada: da aplicação da linguística a linguística transdisciplinar. São Paulo: EDUC, 1992. p. 15-23.

CELANI, M. A. A. Transdisciplinaridade na Linguística Aplicada no Brasil. In: SIGNORINI, I.; CAVALCANTI, M. C. (Orgs.). Linguística Aplicada e Transdisciplinaridade. São Paulo: Mercado de Letras, 1998. p. 129-142.

CELANI, M. A. A. Relevância da linguística aplicada na formulação de uma política educacional brasileira. In: FORTKAMP, M. B. M.; TOMITCH, L. M. B. (Orgs.). Aspectos da linguística aplicada: estudos em homenagem ao professor Hilário Inácio Bohn. Florianópolis: Insular, 2000. p. 1732.

COOK, G. Birds out of Dinosaurs: The Death and Life of Applied Linguistics. Applied Linguistics, Oxford, v. 36, n. 4, p. 425-433, 2015. https://doi.org/10.1093/applin/amv038

CORRÊA, Y.; CRUZ, R. C. Língua Brasileira de Sinais e Tecnologias Digitais. 1. ed. Porto Alegre: Penso, 2019.

DOUGHERTY, D. The Maker Movement. Innovations, Cambridge, v. 7, n. 3, p. 11-14, 2012. https://doi.org/10.1162/INOV a 00135

GESSER, A. LIBRAS? Que língua é essa? Crenças e preconceitos em torno da língua de sinais e da realidade surda. São Paulo: Parábola Editorial, 2009.

GESSER, A. O ouvinte e a surdez: sobre ensinar e aprender a Libras. São Paulo: Parábola Editorial, 2012.

GROSJEAN, F. Individual bilingualism. In. ASHER, R. E. (Ed.). The Encyclopedia of Language and Linguistics. Oxford: Pergamon Press, 1994a. p. 1656-1660.

GROSJEAN, F. Sign bilingualism: Issues. In. ASHER, R. E. (Ed.). The Encyclopedia of Language and Linguistics. Oxford: Pergamon Press, 1994b. p. 3889-3890.

ILDEBRAND, I. S. Língua Brasileira de Sinais e Língua Portuguesa no Ensino Médio: uma proposta de ensino com foco em língua e cultura surda. 2020. 144 f. Dissertação (Mestrado em Linguística Aplicada) - Programa de Pós-Graduação em Linguística Aplicada, Universidade do Vale do Rio dos Sinos, São Leopoldo, 2020.

KLEIMAN, A. B. O estatuto disciplinar da Linguística Aplicada: o traçado de um percurso, um rumo para o debate. In: SIGNORINI, I.; CAVALCANTI, M.C. (Orgs.). Linguística Aplicada e Transdisciplinaridade. São Paulo: Mercado de Letras, 1998. p. 51-77.

LACERDA, C. B. F.; GÓES, M. C. R. (Orgs.) Surdez: processos educativos e subjetividade. São Paulo: Lovise, 2000.

LUDKE, M.; ANDRÉ, M. E. D. A. Pesquisa em educação: abordagens qualitativas. Rio de Janeiro: EPU, 2013.

MAMEDE, S.; PENAFORTE, J. (Orgs.) Aprendizagem Baseada em Problemas: anatomia de uma nova abordagem educacional. Fortaleza: Hucitec, 2001. 
MARTINS, V. R. O. Análise das vantagens e desvantagens da Libras como disciplina curricular no ensino superior. Cadernos do CEOM, Chapecó, v. 21, n. 28, p. 191-206, 2008.

MELLO, D. Contribuições do Design Thinking para a educação: um estudo em escolas privadas de Porto Alegre/RS. 2014. 166 f. Dissertação (Mestrado em Design) - Programa de PósGraduação em Design, Universidade do Vale do Rio dos Sinos, São Leopoldo, 2014.

MEULDER, M. et al. Describe, don't prescribe. The practice and politics of translanguaging in the context of deaf signers. Journal of Multilingual and Multicultural Development, Londres, v. 40, n. 10, p. 892-906, 2019. https://doi.org/10.1080/01434632.2019.1592181

NASCIMENTO, L. C. R.; SOFIATO, C. G. A disciplina de Língua Brasileira de Sinais no Ensino Superior e a formação dos futuros educadores. Educação Temática Digital - ETD, Campinas, v.18, n.2, p. 352-368, 2016. https://doi.org/10.20396/etd.v18i2.8639505

NEIGRAMES, W. P. et al. O ensino de Libras e a Linguística Aplicada: uma ponte possível. Linguagem: Estudos e Pesquisas, Catalão, v. 22, n. 1, p. 67-82, 2018. https://doi.org/10.5216/lep.v22i1.54460

OLIVEIRA, M. C. L. Por uma linguística aplicada mais inclusiva. Calidoscópio, São Leopoldo, v.7, n. 2, p. 93-96, 2009. https://doi.org/10.4013/cld.2009.72.01

OSTERMANN, A. C.; GUIMARÃES, A. M. M. A Linguística Aplicada que se faz 'aqui': dez anos formando doutoras e doutores. Calidoscópio, São Leopoldo, v. 17, n. 4, p. 687-698, 2019. https://doi.org/10.4013/cld.2019.174.01

PEREIRA, M. C. P. A língua de sinais brasileira: análise de material didático de ensino como segunda língua para ouvintes. Linguasagem, São Paulo, n. 1, p. 1-14, 2009.

QUADROS, R. M. Educação de surdos: a aquisição da linguagem. Porto Alegre: Artmed. 1997.

QUADROS, R. M; KARNOPP, L. Língua de Sinais Brasileira: Estudos Linguísticos. Porto Alegre: Artmed, 2004. https://doi.org/10.18309/anp.v1i16.560

SANTOS, E. F. Tecendo leituras nas pesquisas sobre Libras: sentidos atribuídos ao seu ensino na educação superior. In: ALMEIDA, W. G. (Org.). Educação de surdos: formação, estratégias e prática docente. Ilhéus: Editus, 2015. p. 67-91.

https://doi.org/10.7476/9788574554457.0005

SCHMIDT, H. As bases cognitivas da aprendizagem baseada em problemas. In: MAMEDE, S.; PENAFORTE, J. (Orgs.) Aprendizagem Baseada em Problemas: anatomia de uma nova abordagem educacional. Fortaleza: Hucitec, 2001. p. 81-108.

SILVA, I. R. Educação Bilíngue para Surdos e valorização de línguas minoritárias. Estudos Linguísticos, São Paulo, v. 44, n. 2, p. 574-583, 2015.

SOUZA, I. L.; BARCELOS, A. M. F. Onde está a LIBRAS? Uma reflexão sobre a Língua Brasileira de Sinais no cenário da Linguística Aplicada Brasileira. Domínios de Lingu@Gem, Uberlândia, v. 10, n. 3, p. 851-863, 2016. https://doi.org/10.14393/DL23-v10n3a2016-5

SPAGNOLO, C. A Formação Continuada de Professores: O Design Thinking como Perspectiva Inovadora e Colaborativa na Educação. 2017. 221 f. Dissertação (Mestrado em Educação) Programa de Pós-Graduação em Educação, Pontifícia Universidade Católica do Rio Grande do Sul, Porto Alegre, 2017. 
STAKE, R. Pesquisa qualitativa: estudando como as coisas funcionam. São Paulo: Penso, 2011.

VERAS, D. S.; BRAYNER, I. C. S. Atuação Docente: ensino de Libras no Ensino Superior. Revista Trama, Marechal Cândido Rondon, v. 14, n. 32, p. 121- 130, 2018.

Recebido em: 20/04/2020. Aceito em: 19/07/2020. 